\title{
Redução da proteína bruta com suplementação de aminoácidos em rações para alevinos de tambatinga
}

\author{
Maria de Nasaré Bona de Alencar Araripe ${ }^{1}$, Hamilton Gondim de Alencar Araripe ${ }^{2,4}$, João \\ Batista Lopes ${ }^{1}$, Pollyanna Lima de Castro ${ }^{3}$, Tony Ewerton Amorim Braga ${ }^{3}$, Antônio Hosmylton \\ Carvalho Ferreira ${ }^{4}$, Márvio Lobão Teixeira de Abreu $^{1}$
}

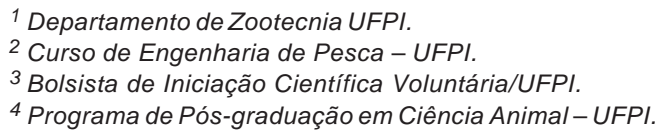

RESUMO - Foram avaliados o desempenho e a composição muscular da carcaça de alevinos de tambatinga, com peso inicial de 6,521 $\pm 0,300 \mathrm{~g}$, alimentados com dietas isoenergéticas, isocálcicas e isofosfóricas contendo 40, 37, 34, 31 ou 28\% de proteína bruta. Os peixes foram mantidos durante 40 dias em tanques de polietileno, com sistema de recirculação de água. No início e final do experimento, os peixes foram pesados e os dados utilizados para avaliação do ganho de peso diário, consumo diário de ração, conversão alimentar aparente, índice de conversão alimentar, consumo diário de proteína, taxa de crescimento específico e taxa de eficiência proteica. No início e final do experimento, foram selecionadas amostras de peixes para análise da composição muscular, e os resultados utilizados para avaliar a eficiência de retenção de proteína e a proporção de proteína e extrato etéreo no ganho de peso. Entre os parâmetros de desempenho, os níveis de PB influenciaram apenas o consumo de proteína e a taxa de eficiência proteica, com efeito linear. Os teores de proteína bruta, a proporção de proteína no ganho de peso e eficiência de retenção de proteína no músculo dos alevinos de tambatinga aumentaram linearmente com a redução de proteína bruta na dieta, enquanto o teor de extrato etéreo e sua proporção no ganho de peso diminuíram. O nível de $28 \%$ de PB, quando há suplementação com aminoácidos, pode ser utilizado em dietas para alimentação dos alevinos de tambatinga, pois não prejudica seu desempenho.

Palavras-chave: composição muscular, desempenho, níveis de proteína, nutrição de peixes

\section{Reduction of crude protein with amino acid supplementation in tambatinga fingerling diets}

\begin{abstract}
This study was developed to evaluate the performance and carcass composition of tambatinga fingerlings, with initial weight of $6.521 \pm 0.300 \mathrm{~g}$, fed with isocaloric, isocalcic and isophosphoric diets $(40,37,34,31$ and $28 \%$ of CP). Fish were cultivated for forty days in polyethylene tanks, with water recirculation system. Fishes were weighed at the beginning and at the end of the trial and the data were used for evaluation of weight gain, feed intake, apparent feed conversion, index of feed conversion, protein intake, specific growth rate and protein efficiency rate. At the beginning and end of the experiment, samples of fishes were selected for analysis of muscle composition, and the results were utilized to assess protein retention efficiency and proportion of protein and ethereal extract at weight gain. Among the performance parameters, crude protein levels influenced only protein intake and protein efficiency rate, with linear effect. Crude protein amount, proportion protein on weight gain and protein retention efficiency of the tambatinga fingerling's muscle, increased linearly with protein reduction in the diet, whereas ethereal extract and its proportion on weight gain decreased. It was concluded that the diet with $28 \%$ of protein can be used for tambatinga fingerlings without affecting performance.
\end{abstract}

Key Words: fish nutrition, muscle composition, performance, protein levels

\section{Introdução}

A proteína é o nutriente que mais diretamente interfere no crescimento do animal e tem influência direta no ganho de peso, na conversão alimentar e na composição da carcaça, mas a utilização de elevado teor proteico na ração não garante melhoria de desempenho. Assim, considerando que os ingredientes proteicos são os de maior custo na composição das rações, muitos pesquisadores têm realizado trabalhos no sentido de diminuir a quantidade de proteína na ração sem interferir negativamente no desempenho dos animais (Fernandes et al., 2000; Vásquez- 
Torres et al., 2002; Sá et al., 2008; Bomfim et al., 2008; Feiden et al., 2009).

Em piscicultura costuma-se trabalhar com dietas de elevados níveis de proteína, o que, frequentemente, resulta em duas situações indesejáveis: o desbalanceamento dos aminoácidos em relação às exigências reais, acarretando a oxidação da cadeia de carbono com desvio do objetivo maior dos aminoácidos, que seria a formação de tecido magro (Ronnestad et al., 2000; Ozorio et al., 2002); e o segundo aspecto está relacionado à elevação da excreção nitrogenada, que pode levar à eutrofização da água (Beveridge, 2004).

É possível diminuir o teor de proteína da ração sem prejudicar o desempenho dos animais, pois a diminuição da proteína nas dietas, apesar de reduzir o fornecimento de nitrogênio e de aminoácidos, pode não causar prejuízos, uma vez que o menor fornecimento de nitrogênio acarreta redução da excreção nitrogenada, o que é desejável para manutenção da qualidade da água. Além disso, a menor quantidade de aminoácidos pode ser corrigida pela suplementação com aminoácidos industriais (Green \& Hardy, 2008; Gaylord \& Barrows, 2009).

Existe um descompasso de tempo entre a absorção dos aminoácidos industriais e a chegada dos aminoácidos oriundos de fontes proteicas nos sítios de absorção para ocorrer a síntese proteica, devido à maior rapidez com que os aminoácidos industriais são absorvidos (Yamada et al., 1981; Baldisseroto, 2009). Entretanto, pesquisas mostram que esse problema pode ser contornado com o fornecimento da ração em várias refeições (Tantikitti \& March, 1995; Rodehutscord et al., 1997; Zarate \& Lovell, 1997; Ambardekar et al., 2009).

Nesse contexto, foi conduzido um experimento para avaliar o efeito da redução da proteína bruta, com suplementação de aminoácidos industriais, sobre o desempenho e a composição de carcaça dos alevinos de tambatinga.

\section{Material e Métodos}

O experimento foi realizado no Laboratório de Pesquisa em Piscicultura (LAPESPI) do Departamento de Zootecnia do Centro de Ciências Agrárias, Universidade Federal do Piauí, utilizando-se 20 tanques de polietileno com capacidade de $1 \mathrm{~m}^{3}$, interligados, formando um sistema de recirculação de água com filtragem biológica e desinfecção por lâmpadas ultravioletas com capacidade de circulação de 22 vezes ao dia. A fonte de abastecimento de água foi um poço tubular, em que a água, ao ser bombeada, era direcionada para uma caixa de 5.000 L, onde recebia oxigenação antes de abastecer os tanques de cultivo.

Foram utilizados 3 mil alevinos de tambatinga que, inicialmente, foram estocados em tanques de fibra de vidro por 15 dias, recebendo ração comercial com 36\% de proteína bruta. Após esse período, os animais foram submetidos a 24 horas de jejum e separados por tamanho utilizando-se seletor de alevinos. Dentro do grupo que apresentava comprimento total entre 3,5 e $4,0 \mathrm{~cm}$, foram selecionados 330 alevinos com peso de 6,521 $\pm 0,300 \mathrm{~g}$, sendo distribuídos, aleatoriamente, 15 exemplares por unidade experimental, em delineamento inteiramente casualizado. Os outros 30 peixes foram sacrificados e colocados em estufa com circulação de ar a $50^{\circ} \mathrm{C}$, por 72 horas, para posterior análise bromatológica da carcaça inicial.

Como tratamentos foram avaliadas cinco dietas isoenergéticas, isocálcicas e isofosfóricas, contendo 40, 37, 34, 31 e 28\% de proteína bruta. Os demais parâmetros nutricionais foram fixados atendendo às exigências nutricionais para peixes onívoros, conforme descrito por Tacon (1990). Procurou-se manter constante as relações metionina+cistina:lisina e treonina:lisina pela suplementação com aminoácidos industriais (Tabela 1).

Os ingredientes das rações foram moídos separadamente para obtenção da mesma granulometria e foram pesados, misturados, e umedecidos utilizando-se água aquecida a $40^{\circ} \mathrm{C}$ em quantidade equivalente a $30 \%$ do peso total dos ingredientes. A mistura foi passada em moinho de carne, para compressão e formação de espaguetes, que foram triturados manualmente, e passados em um conjunto de peneiras granutest, ficando os péletes com granulometria entre 3 e $4 \mathrm{~mm}$. Após esse processo, a ração foi colocada em estufa com circulação de ar, a $50^{\circ} \mathrm{C}$, por 24 horas, e posteriormente colocada em sacos plásticos e acondicionada sob refrigeração até utilização.

Durante o período experimental, que foi de 40 dias, os peixes foram alimentados em quatro refeições (às 8,11 , 14, e 17 h), até saciedade aparente, observando-se o comportamento dos animais e a avidez com que consumiam a ração, evitando-se, dessa forma, sobra de ração na água ou fornecimento escasso.

A temperatura da água foi monitorada diariamente utilizando-se três termômetros digitais com funções de temperatura máxima e mínima, um instalado em um tanque do lado direito, outro do lado esquerdo e outro no filtro. Semanalmente foram aferidos o $\mathrm{pH}$ e os teores de oxigênio dissolvido, amônia e nitrito. O pH e o teor de oxigênio dissolvido foram determinados utilizando-se medidor de $\mathrm{pH}$ e oxímetro digitais, respectivamente, e, para a 
Tabela 1 - Fórmula e composição das rações experimentais

\begin{tabular}{|c|c|c|c|c|c|}
\hline \multirow[t]{2}{*}{ Ingrediente } & \multicolumn{5}{|c|}{ Nível de proteína bruta (\%) } \\
\hline & 40 & 37 & 34 & 31 & 28 \\
\hline Farelo de soja (45\% PB) & 86,41 & 78,12 & 69,36 & 60,34 & 51,28 \\
\hline Farinha de peixe & 0,50 & 0,50 & 0,50 & 0,50 & 0,50 \\
\hline Amido de milho & 2,20 & 2,16 & 2,11 & 2,07 & 2,02 \\
\hline Óleo de soja & 2,34 & 2,08 & 1,81 & 1,59 & 1,32 \\
\hline L-treonina $(98,5 \%)$ & 0,00 & 0,00 & 0,00 & 0,12 & 0,25 \\
\hline Calcáreo calcítico & 0,09 & 0,08 & 0,07 & 0,06 & 0,05 \\
\hline Fosfato bicálcico & 0,91 & 0,99 & 1,08 & 1,16 & 1,27 \\
\hline Premix vitamínico e mineral ${ }^{1}$ & 0,30 & 0,30 & 0,30 & 0,30 & 0,30 \\
\hline Cloreto de sódio & 0,39 & 0,12 & 0,05 & 0,11 & 0,11 \\
\hline \multicolumn{6}{|l|}{ Valores calculados ${ }^{2}$} \\
\hline Amido (\%) & 16,91 & 21,31 & 25,67 & 29,94 & 34,28 \\
\hline Fibra bruta (\%) & 4,80 & 4,50 & 4,18 & 3,84 & 3,50 \\
\hline Cálcio total (\%) & 0,50 & 0,50 & 0,50 & 0,50 & 0,50 \\
\hline Fósforo disponível (\%) & 0,35 & 0,35 & 0,35 & 0,35 & 0,35 \\
\hline Lisina digestível $(\%)^{4}$ & 2,20 & 2,05 & 2,05 & 2,05 & 2,05 \\
\hline Metionina + cistina digestível $(\%)^{4}$ & 1,08 & 1,01 & 0,97 & 0,97 & 0,97 \\
\hline Treonina digestível $(\%)^{4}$ & 1,42 & 1,31 & 1,19 & 1,19 & 1,19 \\
\hline Triptofano digestível $(\%)^{4}$ & 0,50 & 0,46 & 0,42 & 0,37 & 0,32 \\
\hline Metionina + cistina:lisina digestível $^{4}$ & 49,07 & 49,32 & 47,39 & 47,40 & 47,43 \\
\hline Treonina:lisina digestível ${ }^{4}$ & 64,34 & 63,99 & 58,29 & 58,17 & 58,18 \\
\hline Triptofano:lisina digestível ${ }^{4}$ & 22,80 & 22,50 & 20,31 & 18,05 & 15,78 \\
\hline
\end{tabular}

determinação de amônia e nitrito, utilizou-se o método colorimétrico. Quando observados valores fora dos padrões indicados por Boyd (1990) para águas de piscicultura, eram realizadas a sifonagem dos tanques e renovação da água do sistema.

Ao final do experimento, foi aferido o peso dos peixes e selecionada uma amostra de 33\% dos peixes de cada repetição (cinco exemplares) com peso mais próximo da média. Os peixes selecionados foram insensibilizados, eutanasiados, e, assim como os 30 alevinos selecionados no início do experimento, foram descamados, descabeçados e as nadadeiras retiradas. Foram eviscerados, picados e colocados em estufa com circulação de ar, a $50^{\circ} \mathrm{C}$ por 72 horas, para posterior análise bromatológica da carcaça final, seguindo os procedimentos recomendados pela AOAC (1990).

Para cada parcela experimental, foram avaliados os parâmetros de desempenho, composição muscular e eficiência de utilização de nutrientes, de acordo com as equações:

Ganho de peso diário $(\mathrm{GPD})=(\mathrm{Pf}-\mathrm{Pi}) / \mathrm{T}$;

Consumo diário de ração $(\mathrm{CDR})=\mathrm{CR} / \mathrm{T}$;
Conversão alimentar aparente $(\mathrm{CAA})=\mathrm{CR} / \mathrm{GP}$;

Consumo diário de proteína bruta $(\mathrm{CDPB})=(\mathrm{CDR} \times$ $\% \mathrm{~PB}) / 100$;

Taxa de crescimento específico $(\mathrm{TCE})=[(\ln \mathrm{Pf}-\ln \mathrm{Pi})$ $\times 100] / \mathrm{T}$;

Taxa de eficiência proteica $($ TEP $)=$ GP $/$ CPB;

Eficiência de retenção de proteína bruta $(\mathrm{ERPB})=$ $\{[(\mathrm{PBf} \times \mathrm{Pf})-(\mathrm{PBi} \times \mathrm{Pi})] \times 100\} / \mathrm{CPB}$;

Proporção de proteína no ganho de peso $(\mathrm{PBGP})=$ $\{[(\mathrm{PBf} \times \mathrm{Pf})-(\mathrm{PBi} \times \mathrm{Pi})] \times 100\} /(\mathrm{Pf}-\mathrm{Pi})$;

Proporção de extrato etéreo no ganho de peso $(\mathrm{EEGP})=$ $\{[($ EEf $\times$ Pf $)-$ EEi $\times$ Pi $)] \times 100\} /(\mathrm{Pf}-\mathrm{Pi})$;

em que: $\mathrm{Pf}$-peso final; $\mathrm{Pi}$ - peso inicial; $\mathrm{GP}$ - ganho de peso; $\mathrm{T}$ - tempo experimental; CR - consumo de ração; CPB consumo de proteína bruta; $\mathrm{PB}$ - teor de proteína bruta da ração; PBf - proteína bruta muscular final; EEf - extrato etéreo muscular final; $\mathrm{PBi}$ - proteína bruta muscular inicial; EEi-extrato etéreo muscular inicial.

Os dados obtidos foram submetidos à análise de regressão polinomial, de acordo com os procedimentos do Statistical Analysis System (SAS, 1986). 


\section{Resultados e Discussão}

As médias das temperaturas máximas e mínimas da água durante o período experimental foram de $31 \pm 1,78^{\circ} \mathrm{C}$ e $26,48 \pm 0,5{ }^{\circ} \mathrm{C}$, respectivamente. $\mathrm{O}$ teor de oxigênio dissolvido foi 6,24 $\pm 0,55 \mathrm{mgL}^{-1}$; pH, 6,38 $\pm 0,57$; amônia, $0,19 \pm 0,08 \mathrm{mgL}^{-1}$ e nitrito, $0,02 \pm 0,01 \mathrm{mgL}^{-1}$. Não foram observadas diferenças nesses parâmetros entre as unidades experimentais, o que provavelmente esteve relacionado à circulação da água, uma constatação positiva por garantir condições ambientais homogêneas em todos os tratamentos.

Não foram observadas diferenças significativas no ganho de peso diário, no consumo diário de ração, na conversão alimentar e na taxa de crescimento específico dos alevinos de tambatinga no período experimental (Tabela 2).

$\mathrm{O}$ valor obtido para a taxa de crescimento específico dos alevinos alimentados com ração contendo $28 \%$ PB foi de 5,69\%, valor superior ao de $2,41 \%$ obtido com o nível de 28\% PB + amilase (Nunes et al., 2006) e aos 1,98\% observados para tambatingas alimentados com 38\% PB (Paula et al., 2009), o que reforça a afirmativa de que a suplementação com aminoácidos tem efeito positivo no desempenho de alevinos dessa espécie.

Trabalhos realizados com truta e tilápia comprovam que esses peixes alimentados com ração contendo reduzido nível de proteína e suplementada com aminoácidos podem manter desempenho e taxas de crescimento específico compatíveis com os observados nessas mesmas espécies quando alimentadas com rações de níveis proteicos mais elevados e sem suplementação aminoacídica (Yamamoto et al., 2005; Furuya et al., 2005; Bomfim et al., 2008).

Na formulação das rações experimentais, o nível proteico mais baixo (28\% PB) foi o que recebeu a maior suplementação com aminoácidos, enquanto a ração com maior nível proteico (40\% PB) não teve suplementação aminoacídica. Considerando que a redução da proteína na ração aumentou a taxa de eficiência proteica $(\mathrm{P}<0,05)$ apesar da queda significativa no consumo diário de proteína, tem-se um indicativo de que os aminoácidos industriais podem garantir o ganho de peso. Como os aminoácidos industriais estão sujeitos à baixa utilização, em decorrência de sua rápida absorção (Yamada et al., 1981; Baldisseroto, 2009), essa utilização pelos alevinos de tambatinga pode ter sido influenciada pelo fornecimento da ração, que foi realizado em quatro refeições e com repasses sucessivos, o que provavelmente evitou a elevação da concentração plasmática de aminoácidos e compatibilizou a velocidade de síntese proteica (Rodehutscord et al., 1997; Zarate \& Lovell, 1997; Tantikitti \& March, 1995).

O aumento da eficiência proteica com a redução da proteína bruta, associado ao fato de a ração com $40 \%$ PB ter níveis de aminoácidos ligados à proteína mais elevados que a ração com 28\% PB mesmo após a suplementação aminoacídica indica que o excesso de aminoácidos da ração com $40 \%$ PB não foi eficientemente utilizado, o que está de acordo com informações de Yamamoto et al. (2005) e Ahmed \& Khan (2004) de que os peixes, assim como os demais animais, têm exigências por um balanceamento correto de aminoácidos.

A análise muscular do tambatinga (Tabela 3) comprova que a redução dos níveis de proteína bruta teve efeito linear significativo em todos os parâmetros estudados, tendo em vista o decréscimo do extrato etéreo muscular e da proporção de extrato etéreo no ganho de peso com a redução do nível de proteína bruta da ração.

O decréscimo linear observado no teor de extrato etéreo muscular está em consonância com o relatado por Cotan et al. (2006) de que o excesso de proteína pode ser direcionado para utilização como energia, acarretando aumento na quantidade de extrato etéreo muscular. Como as dietas experimentais foram isoenergéticas e isofosfóricas, este fato reforça a ideia de que o maior teor de extrato etéreo muscular é consequência do excesso de proteína da dieta, que acarretou excesso de aminoácidos, os quais devem ter sido catabolizados, favorecendo a oxidação das cadeias de carbonos dos aminoácidos proporcionando formação de tecido adiposo (Tantikitti \& March, 1995; Shuhmacher et al., 1997; Ozório et al., 2002; Amogh et al., 2009; Sardar et al., 2009).

Tabela 2 - Desempenho de alevinos de tambatinga alimentados com rações formuladas com diversos níveis de proteína bruta

\begin{tabular}{|c|c|c|c|c|c|c|}
\hline \multirow[t]{2}{*}{ Parâmetro } & \multicolumn{5}{|c|}{ Nível de proteína bruta (\%) } & \multirow[t]{2}{*}{$\mathrm{CV}$} \\
\hline & 40 & 37 & 34 & 31 & 28 & \\
\hline Ganho de peso diário (g/dia) & 1,75 & 1,77 & 1,79 & 1,75 & 1,69 & 5,65 \\
\hline Consumo diário de ração (g/dia) & 1,71 & 1,71 & 1,73 & 1,72 & 1,72 & 3,24 \\
\hline Conversão alimentar aparente & 0,98 & 0,97 & 0,97 & 0,99 & 1,02 & 3,69 \\
\hline Taxa de crescimento específico (\%) & 5,67 & 5,71 & 5,76 & 5,74 & 5,69 & 3,18 \\
\hline Consumo diário de proteína bruta $(\mathrm{g} / \mathrm{dia})^{1}$ & 0,68 & 0,63 & 0,59 & 0,53 & 0,48 & 2,97 \\
\hline Taxa de eficiência proteica $(\%)^{2}$ & 2,56 & 2,79 & 3,04 & 3,28 & 3,52 & 3,70 \\
\hline
\end{tabular}

Taxa de eficiência proteica $(\%)^{2}$

${ }^{1}$ Efeito linear ( $\left.y=0,0096+0,0168 x, r^{2}=0,99, P<0,05\right)$
${ }^{2}$. coeficiente de variac̃a.

${ }^{2}$ Efeito linear $\left(\mathrm{y}=5,7513-0,0798 \mathrm{x}, \mathrm{r}^{2}=0,99, \mathrm{P}<0,05\right)$. 
Tabela 3 - Umidade, deposição de proteína bruta e extrato etéreo, eficiência de retenção de proteína e proporções de proteína e extrato etéreo no ganho de peso de alevinos de tambatinga alimentados com rações formuladas com diversos níveis de proteína bruta

\begin{tabular}{|c|c|c|c|c|c|c|}
\hline \multirow[t]{2}{*}{ Parâmetro } & \multicolumn{5}{|c|}{ Nível de proteína bruta (\%) } & \multirow[t]{2}{*}{$\mathrm{CV}$} \\
\hline & 40 & 37 & 34 & 31 & 28 & \\
\hline Umidade muscular, na matéria natural ${ }^{1}$ & 75,18 & 75,26 & 75,13 & 75,12 & 74,44 & 0,49 \\
\hline Extrato etéreo muscular, na matéria natural ${ }^{3}$ & 6,13 & 5,36 & 4,40 & 3,70 & 3,17 & 6,09 \\
\hline Eficiência de retenção de proteína ${ }^{4}$ & 46,66 & 47,89 & 51,39 & 53,87 & 57,26 & 3,66 \\
\hline Proporção de proteína no ganho de peso ${ }^{5}$ & 16,28 & 16,45 & 16,91 & 17,15 & 18,19 & 1,83 \\
\hline
\end{tabular}

CV - coeficiente de variação.

${ }^{1}$ Efeito linear $\left(y=73,151+0,055 \mathrm{x}, \mathrm{r}^{2}=0,61, \mathrm{P}<0,05\right)$.

${ }^{2}$ Efeito linear $\left(\mathrm{y}=-0,1393 \mathrm{x}+21,655, \mathrm{r}^{2}=0,90, \mathrm{P}<0,05\right)$.

3 Efeito linear $\left(\mathrm{y}=-3,977+0,249 \mathrm{x}, \mathrm{r}^{2}=0,97, \mathrm{P}<0,05\right)$.

${ }^{4}$ Efeito linear $\left(\mathrm{y}=82,120-0,898 \mathrm{x}, \mathrm{r}^{2}=0,97, \mathrm{P}<0,05\right)$.

${ }^{5}$ Efeito linear $\left(\mathrm{y}=-0,152+22,172, \mathrm{r}^{2}=0,91, \mathrm{P}<0,05\right)$.

${ }^{6}$ Efeito linear $\left(\mathrm{y}=-4,417+0,271 \mathrm{x}, \mathrm{r}^{2}=0,97, \mathrm{P}<0,05\right)$.

Várias pesquisas indicam que o excesso de proteína aumenta o teor de lipídios na carcaça dos peixes (Carneiro et al., 1994; Henandez et al., 1995; Araripe \& Ogawa, 1996; Abimorad \& Carneiro, 2007), o que não é desejável, por desviar o uso da proteína de sua principal função, que é a produção de tecido magro. Além disso, a utilização de proteína para produção de tecido gordo acarreta gasto energético desnecessário, aumentando a atividade enzimática envolvida na síntese gliconeogênica, elevando a excreção nitrogenada e acarretando prejuízo ao animal e ao ambiente (Saavedra et al., 2009; Furuya, 2007, Bechara et al., 2005; Beveridge, 2004; Carter et al., 1994). Esses resultados foram confirmados neste trabalho, uma vez que a redução da proteína bruta na ração provocou aumento da proteína muscular e redução do extrato etéreo muscular.

Reforçando essa afirmativa, houve aumento $(\mathrm{P}<0,05)$ na proporção de proteína no ganho de peso e queda na proporção do extrato etéreo no ganho de peso com a redução da proteína bruta da ração. Também foi observado aumento linear $(\mathrm{P}<0,05)$ da eficiência de retenção de proteína com a redução dos níveis proteicos, resultado semelhante ao observado por Yamamoto et al. (2005) em trutas (Oncorhynchus mykiss) e tilápias-do-nilo (Oreochromis niloticus), que apresentaram menor teor de gordura corporal quando alimentadas com ração contendo 27,5\% de PB (Furuya et al., 2005).

A redução do nível de proteína em rações para peixes é importante porque diminui a quantidade de nitrogênio na água (Furuya et al., 2005; Brandão, 2006) e, no caso dos alevinos de tambatinga, a redução da proteína de 40 para $28 \%$ com a suplementação com aminoácidos não afetou o ganho de peso e ainda proporcionou menor teor de gordura muscular.

\section{Conclusões}

O nível de 28\% de PB, quando há suplementação com aminoácidos, pode ser utilizado em dietas para alevinos de tambatinga, pois não prejudica o desempenho dessa espécie.

\section{Referências}

ABIMORAD, E.G.; CARNEIRO, D.J. Digestibility and performance of pacu (Piaractus mesopotamicus) juveniles fed diets containing different protein, lipid and carbohydrate levels. Aquaculture Nutrition, v.13, p.1-9, 2007.

AHMED, I.; KHAN, M.A. Dietary lysine requirement of fingerling Indian major carp, Cirrhinus mrigala (Hamilton). Aquaculture, v.235, p.499-511, 2004.

ALMEIDA, L.C.; LUNDSTEDT, L.M.; MORAES, G. Digestive enzyme responses of tambaqui (Colossoma macropomum) fed on different level of protein and lipid. Aquaculture Nutrition, v.12, n.6, p.446-450, 2006.

AMBARDEKAR, A.A.; REIGH, R.C.; WILLIAMS, M.B. Absorption of amino acids from intact dietary proteins and purified amino acid supplements follows different time-courses in channel catfish (Ictalurus punctatus). Aquaculture, v.291, n.3-4, p.179-187, 2009.

AMOGH, A.A.; REIGH, R.C.; WILLIAMS, M.B. Absorption of amino acids from intact dietary proteins and purified amino acid supplements follows different time-courses in channel catfish (Ictalurus punctatus). Aquaculture, v.291, p.179-187, 2009.

ARARIPE, M.N.B.A.; OGAWA, M. Influência de diferentes níveis de proteína e energia sobre o desempenho dos alevinos de tambaqui. In: REUNIÃO DA SOCIEDADE BRASILEIRA DE ZOOTECNiA, 32., 1996, Fortaleza. Anais... Viçosa, MG: Sociedade Brasileira de Zootecnia, 1996. v.2, p.472-473.

ASSOCIATION OF OFFICIAL ANALYTICAL CHEMISTRY AOAC. Official methods of analyse. 15.ed. Arlington: AOAC, 1990. 1298p.

BALDISSEROTO, B. Fisiologia de peixes aplicada à piscicultura. 2.ed. Santa Maria: UFSM, 2009. 211p.

BECHARA, J.A.; ROUX, J.P.; DÍAZ, J.R. et al. The effect of dietary protein level on pond water quality and feed utilization efficiency of pacú Piaractus mesopotamicus (Holmberg, 1887. Aquaculture Research, v.36, p.546-553, 2005. 
BEVERIDGE, M.C.M. Cage aquaculture. 3.ed. United Kingdom: Blackwel, 2004. 367p.

BOMFIM, M.A.D.; LANNA, E.A.T.; DONZELE, J.L. et al. Redução de proteína bruta com suplementação de aminoácidos, com base no conceito de proteína ideal, em rações para alevitos de tilápia-do-nilo. Revista Brasileira de Zootecnia, v.37, n.10, p.1713-1720, 2008.

BOYD, C.E. Water quality management for ponds fish culture. Development in aquaculture and fisheries science. Amsterdam: Elsevier Scientific Publishing Company, 1990. 482p.

BRANDÃO, L.V. Suplementação de metionina e/ou lisina em rações com níveis decrescentes dos teores de proteína para juvenis de tambaqui, Colossoma macropomum. 2006. 46f. Dissertação (Mestrado em Biologia de Água Doce e Pesca Interior) - Universidade Federal da Amazônia/Instituto de Pesquisas da Amazônia, Manaus.

CARNEIRO, D.J.; FRAGNITO, P.S.; MALHEIROS, E.B. Influence of carbohydrate and energy level on growth and body composition of tambacu, a hybrid of tambaqui (Colossoma macropomum) and pacu (Piaractus mesopotamicus). Aquaculture, v.124, p.129-130, 1994.

CARTER, C.; OWEN, S.; HE, Z. et al. Determination of protein synthesis in rainbow trout, Oncorhynchus mykiss, using a stable isotope. Journal of Experimental Biology, v.189, n.1, p.279-284, 1994.

COTAN, J.L.V.; LANNA, E.A.T.; BOMFIM, M.A.D. et al. Níveis de energia digestível e proteína bruta em rações para alevinos de lambari tambiú. Revista Brasileira de Zootecnia, v.35, n.3, p.634-640, 2006.

FEIDEN, A.; SIGNOR, A.A.; BOSCOLO, W.R. et al. Exigência de proteína de alevinos de piavuçú. Ciencia Rural, v.39, n.3, p.859-865, 2009.

FERNANDES, J.B.K.; CARNEIRO, D.J.; SAKAMURA, N.K. Fontes e níveis de proteína bruta em dietas para alevinos de pacu (Piaractus mesopotamicus). Revista Brasileira de Zootecnia, v.29, n.3, p.646-653, 2000.

FURUYA, W.M.; PEZZATO, L.E.; PEAZZATO, A.C. et al. Coeficientes de digestibilidade e valores de aminoácidos digestíveis de alguns ingredientes para a tilápia do Nilo (Oreochromis niloticus). Revista Brasileira de Zootecnia, v.30, n.4, p.1143-1149, 2001.

FURUYA, W.M.; BOTARO, D.; MACEDO, R.M.G. et al. Aplicação do conceito de proteína ideal para redução dos níveis de proteína em dietas para tilápia do Nilo (Oreochromis niloticus). Revista Brasileira de Zootecnia, v.34, n.5, p.1433-1441, 2005.

FURUYA, W.M. Redução do impacto ambiental por meio da ração. In: SEMINÁRIO DE AVES E SUÍNOS, 7.; SEMINÁRIO DE AQÜICULTURA, MARICULTURA E PESCA, 3., 2007, Belo Horizonte. Anais... Concórdia: EMBRAPA/CNPSA, 2007. p.121-139.

GAYLORD, T.G.; BARROWS, F.T. Multiple amino acid supplementation to reduce dietary protein in plant-based rainbow trout, Oncorhynchus mikiss, feeds. Aquaculture, v.287, p.180-184, 2009.

GREEN, J.A.; HARDY, R.W. The effects of dietary protein:energy ration and amino acid pattern on nitrogen utilization and excretion of rainbow trout Oncorhynchus mykiss (Walbaum). Journal of Fish Biology, v.73, p.663-682, 2008.

HERNANDEZ, M.; TAKEUCHI, T.; WATANABE, T. Effect of dietary energy sources on the utilization of protein by Colossoma macropomum fingerlings. Fisheries Science, v.61, n.3, p.507-511, 1995.

INSTITUTO BRASILEIRO DO MEIO AMBIENTE E DOS RECURSOS NATURAIS RENOVÁVEIS - IBAMA. Estatística da Pesca 2006 Brasil: grandes regiões e unidades de federação. Brasília: IBAMA, 2008. 174p.

NUNES, E.S.S.; CAVERO, B.A.S.; PEREIRA-FILHO, M. et al. Enzimas digestivas exógenas na alimentação de juvenis de tambaqui. Pesquisa Agropecuária Brasileira, v.41, n.1, p.139-143, 2006.
OZORIO, R.O.A.; BOOMS, G.H.R.; HUISMAN, E.A. et al. Changes in amino acid composition inthe tisúes of African cat fish (Clarias gariepinus) as a consequence of dietary carnitine supplements. Journal of Applied Ichthyology, v.18, p.140-147, 2002.

PAULA, F.G.; SILVA, P.C.; OLIVEIRA, R.P. et al. Desempenho produtivo do tambaqui (Colossoma macropomum), da pirapitinga (Piaractus brachypomum) e do híbrido tambatinga (C. macropomum fêmea x $P$. brachypomum macho) mantidos em viveiros fertilizados. In: REUNIÃO ANUAL DA SOCIEDADE BRASILEIRA DE ZOOTECNIA, 46., 2009. Maringá. Anais... Maringá: Sociedade Brasileira de Zootecnia, 2009b. (CD-ROM)

RODEHUTSCORD, M.; BECKER, A.; PACK, M. et al. Response of rainbow truot (Oncorhinchus mykiss) to supplements of individual essential amino acids in a semipurified diet, including an estimation of the maintenance requirement for essential amino acids. Journal of Nutrition, v.127, p.1166-1175, 1997.

RONNESTAD, I.; CONCEIÇÃO, L.E.C.; ARAGÃO, C. et al. Free amino acids are absorbed fase and assimilated more efficiently than protein in post larval Senegal sole (Solea senegalensis) Journal of Nutrition, v.130, p.2809-2812, 2000.

ROSTAGNO, R.S.; ALBINO, L.F.T.; DONZELE, J.L. et al. Tabelas brasileiras para aves e suínos: composição de alimentos e exigências nutricionais. 2.ed. Viçosa, MG: UFV. 2005. 186p.

SÁ, R.; POUSÃO-FERREIRA, P.; OLIVA-TELES, A. Dietary protein requirement of white sea bream (Diplodus sargas) juveniles. Aquaculture Nutrition, v.14, p.309-317, 2008.

SAAVEDRA, M.; POUSÃO-FERREIRA, P.; YÚFERA, M. et al. A balance amino acid diet imptoves Diplodus sargus larval quality and reduce nitrogen excretion. Aquaculture Nutrition, v.15, p.517-524, 2009.

SARDAR, P.; ABID, M.; RANDHAWA, H.S. et al. Effect of dietary lysine and methionine supplementation on growth, nutrient utilization, carcass compositions and haemato-biochemical status in Indian Major Carp, Ruho (Labeo rohita H.) fed soy proteinbased diet. Aquaculture Nutrition, v.15, p.339-346, 2009.

SHUHMACHER, A.; WAX, C.; GROPP, J.M. Plasma amino acid in rainbow trout (Oncorhynchus mykiss) fed intact protein or a crystalline amino acid diet. Aquaculture, v.151, p.15-28, 1997.

SILVA, J.A.M.; PEREIRA-FILHO, M.; CAVERO, B.A.S. et al. Digestibilidade aparente dos nutrientes e energia de ração suplementada com enzimas digestivas exógenas para juvenis de tambaqui (Colosssoma macropomum Cuvier, 1818). Acta Amazonica, v.37, n.1, p.157-164, 2007.

STATISTICAL ANALYSIS SYSTEM - SAS. SAS System for linear models. Cary: SAS Institute, 1986. (CD-ROM).

TACON, A.G.J. Standart methods for the nutrition and feeding of farmed fish and shrimp. The essential nutrients. Argent Laboratories Press: Washington, 1990. v.1, 95p.

TANTIKITTI, C.; MARCH, B.E. Dinamics of plama free amino acid in rainbow trout (Oncorhynchus mykiss) under variety of dietary conditions. Fish Physiology Biochemistry, v.14, p.179-194, 1995.

VÁSQUES-TORRES, W.; PEREIRA-FILHO, M.; CASTELLANOS, J.A.A. Exigência de proteína, carbohidratos y lípidos em dietas para juveniles de cachama blanca Piaractus brachypomus. In: JORNADA DE ACUICULTURA, 8., 2002, Villavicencio. Anais.. Los Llanos: Universidad de Los Llanos, 2002. p.7-21.

YAMADA, S.; SIMPSON, K L; TANAKA, Y. et al. Plasma amino acid changes in rainbow trout force-fed casein and corresponding amino acid mixture. Bulletin Japonese Society Science Fisheries, v.47, p.1035-1040, 1981.

YAMAMOTO, T.; SUGITA, T.; FURUITA, H. Essential amino acid supplementation to fish meal-based diets with low protein to energy ration improves the protein utilization in juvenile raimbow trout Oncorhinchus mykiss. Aquaculture, v.246, n.1-4, p.379-391, 2005.

ZARATE, D.D.; LOVELL, R.T. Free lysine (L-lysine. $\mathrm{HCl}$ ) is utilized for growth less efficiently than protein-bound lysine (soybean meal) in pratical diets by young channel catfish (Ictalurus puntactus). Aquaculture, v.159, n.1/2, p.87-100, 1997. 